\title{
Erratum to: Contextualizing the subjectivist-objectivist debate in entrepreneurship using engineering, art, craft, and bricolage
}

\author{
Reed E. Nelson ${ }^{1}$ - Carlos Rodriguez-Lluesma ${ }^{2}$. \\ Yosem Eduardo Companys ${ }^{3} \cdot$ Bryan T. Stinchfield $^{4}$
}

Published online: 13 September 2017

(C) Springer Science+Business Media, LLC 2017

\author{
Erratum to: Int Entrep Manag J (2017) \\ https://doi.org/10.1007/s11365-017-0471-6
}

In the original publication of the article, the author name Carlos Rodriguez-Lluesma was incorrectly written as Carlos Rodriquez-Lluesma.

The original article has been corrected.

The online version of the original article can be found at https://dx.doi.org/10.1007/s11365-017-0471-6

\author{
Bryan T. Stinchfield \\ bryan.stinchfield@fandm.edu \\ Reed E. Nelson \\ renelson@siu.edu \\ Carlos Rodriguez-Lluesma \\ clluesma@iese.edu \\ Yosem Eduardo Companys \\ companys@stanford.edu
}

1 UNINOVE, São Paulo, Brazil

2 IESE Business School, Barcelona, Spain

3 Stanford University, Stanford, USA

4 Franklin \& Marshall College, Lancaster, USA 